\title{
HCl 2.0? usability meets Web 2.0
}

\author{
Alan Dix \\ Computing Department, InfoLab21 \\ Lancaster University \\ Lancaster, LA1 4WA, UK \\ +441524510319 \\ alan@hcibook.com
}

\author{
Laura Cowen \\ User Technologies, IBM UK Ltd \\ MP 095, Hursley Park \\ Winchester, SO21 2JN \\ +44 1962815622 \\ laura_cowen@uk.ibm.com
}

\author{
http://www.hcibook.com/papers/HCl2007-HCl-2.0-panel/ \\ http://lancs.facebook.com/group.php?gid=2390506988
}

\begin{abstract}
The web has already dramatically changed society, but the web itself is changing. Web2.0 sites mean that users have become the producers of content and the designers of each others' viewing experience. Technologies such as AJAX combined with public Javascript libraries have allowed applications to be deployed that once would have required extensive programming. Open APIs and mashups make it difficult to tell the difference between a service, and application or a web page. So what are the challenges for HCI when every user is designer, and every menu a different behaviour, when experience outranks efficiency, and connectivity replaces consistency?
\end{abstract}

\section{Categories and Subject Descriptors}

H.5.5 [Information Interfaces and Presentation]: HCI

\section{General Terms}

Design, Human Factors.

\section{Keywords}

Web 2.0, user experience, end-user programming, AJAX, social networking

\section{INTRODUCTION}

Anyone working in human-computer interaction, whether an academic or a practitioner, will lead a life infused if not dominated by the internet and the web. In society more broadly, internet shopping has become ubiquitous and the web has ceased to be a matter of news and has become simply the normal way in which we find out the train time or fill in a tax return.

However, the web itself is changing; young people live in the world of MySpace and Facebook; applications that once ran on the desktop are now running interactively online. Whether this is a step change or simply an evolution, something is

(C) Alan Dix and Laura Cowen, 2007 Published by the British Computer Society Volume 2 Proceedings of the 21st BCS HCI Group Conference

HCI 2007, 3-7 September 2007, Lancaster University, UK Devina Ramduny-Ellis \& Dorothy Rachovides (Editors) happening, and whether it is over-hyped or under-studied, certainly Web2.0 is hot news .

In HCI we cannot afford to neglect this phenomenon. As practitioners we need to know how to design effectively for changing technology and changing use patterns. As academics we need to distil which things are simply old problems in new clothes and which are fundamental shifts that we need to study, not just because they are "this year's story" but because they are the current manifestation of long-term issues.

This panel will bring together a selection of practitioners and academics, some with answers and all with questions, trying to make sense of this emerging picture.

\section{WHAT IS WEB 2.0}

The term Web2.0 was coined by O'Reilly Media [9] to describe a change in emphasis in web applications and technologies. They used a number of pairwise comparisons to visualize the differences: Wikipedia vs. Britannia online, taxonomies vs. folksonomies etc.

Part of this is a technological view: the "web as platform" changing the ways applications are delivered and, perhaps, become services rather than applications in the process. Part is a social view where the web is seen much more as created from the 'bottom' up by the individual users, rather than top down from large companies.

The two sometimes get confused and it is not clear whether these are two separate phenomena or in some way linked. However, certainly in the growth of mashups, these come together as applications are chopped and diced and remixed by savvy users.

Web 2.0 gets linked occasionally with the Semantic Web, although the two are almost the antithesis in terms of spirit and ethos. While the Semantic Web emphasizes rigid standardised semantics, Web 2.0 is more abut emergent phenomena. This is perhaps epitomised by that central Semantic Web concept of the RDF ontology, in contrast to the proliferation of very individual tagging schemes of Web 2.0 applications and their emergent folksonomies.

However, the Semantic Web and Web 2.0 both share common ultimate goal in making the web a more open platform with interchangeable services. Indeed there is ongoing work on mining folksonomies to find emergent ontological structure within them (for example [5]), so it may even be that Web 2.0 and the Semantic Web converge. 


\section{HCI ISSUES FOR WEB 2.0}

\subsection{Social Experience as Product}

Issues of user experience have taken centre stage over recent years, not least because the web has been gradually transforming former software products into services. Wherever end users have choice, user experience becomes critical. In addition, many Web 2.0 sites are about social networking, personal identity. Functionality is important, but the function may be fun, meeting someone or 'hanging around' ... click counts do not give adequate measures!

It is important when considering this to understand the difference between 'chocolate bar' and 'baked bean' products. If you have a room full of children, you can give them baked beans knowing at least most will be satisfied - baked beans are good enough. However, if you give 100 children pocket money and let them loose in a sweet shop they all will get something different - if a chocolate bar is 'good enough' no one will buy it, it has to be best for at least someone. Traditional application design has followed the 'baked bean' model looking at broad user groups and often purchased at a corporate level. With low barriers to entry and broad choice, web products have to be the best for some, not good enough for all.

\subsection{The User as Designer}

In social networking sites such as YouTube, MySpace or Facebook, the page you see is the product of not just the site itself, but also of the owner of the page. Some sites are quite uniform in their appearance, differing mainly in personal content. Other sites, however, allow personalisation ranging from simple re-skinning and colour schemes, to more radical configuration, and in some cases full HTML and Javascript content. Even when we know what 'usability' means for such sites: How do the site owners design usability into a radically configurable site? What about consistency? How do we effectively communicate with 10 million end-user designers?

\subsection{AJAX and Toolkits}

While distancing ourselves from some of the AJAX = Web 2.0 confusions, the two do have connections; not least in that AJAX has been an essential technology in allowing web-based applications to compete with their desktop cousins. However using AJAX means that every application becomes a distributed application with all the potential usability issues that this entails [3] and the complications of programming asynchronous systems. Also virtually every web page designer ends up effectively designing their own widgets. For 20 years the ubiquity of a small number of windowing platforms has meant that the issues of fine design in simple widgets could be ignored by all but a few system developers. Now we all need to learn these lessons again to avoid the horrors of jumping Javascript menus [4]. As every web page becomes a user interface: How do we effectively communicate appropriate usability advice? Can widely used Javascript toolkits such as MIT Prototype library or Yahoo! YUI 'build in' usability so that enddevelopers need to know less?

\subsection{Democratisation of Media}

Increasingly events are being reported using and through personal images: the shaking video of the dust- and panic-filled fall of the Twin Towers, or the approaching tsunami. Now, through YouTube and blogs, our individual and personal recordings become the shared memory and history escapes the hegemony of the media barons and government propaganda. But is there a danger in these democratised, but fragmented, images and vignettes; do we risk losing the threads that have traditionally been provided by the established media?
The UK Education Minister, Alan Johnson, recently recommended using Wikipedia in schools sparking widespread debate on the scholarship and reliability of open-authorship media. In HCI are we also too reliant on web sources ... even Nielsen gained his notoriety through a newsfeed!

\section{WEB 2.0 DEBATE}

There is a growing recognition of the need to understand how usability and Web 2.0 phenomena interact and whether we need to change some of our conceptions of usability in order to meet the challenges of Web 2.0. The topic has already sparked several panels at Web conferences and sessions on related topics at CHI [2] and DIS [6]. There have also been recent articles in Interfaces [11] and Interactions [7] and we can expect many more to come. Perhaps predictably Nielsen has complained that Web 2.0 is 'neglecting good design' [1], but work reported in this conference [10] suggests that some apparently 'bad usability' in Web 2.0 sites is actually good design! Nielsen's remarks have triggered substantial comment from the Web20 community and even a comic strip [8].

We hope this panel will contribute to this debate and if not answer every question at least expose crucial issues for the future ... for your say join the debate in facebook.

\section{REFERENCES}

[1] BBC News. Web 2.0 'neglecting good design'. 14 May 2007 (reporting Jakob Nielsen) http://news.bbc.co.uk/1/hi/technology/6653119.stm

[2] Degler, D., Henninger, S., and Battle, L. Semantic web HCI: discussing research implications. In $\mathrm{CHI}$ '07 Extended Abstracts. ACM Press, 2007, 1909-1912.

[3] Dix, A. Que sera sera - The problem of the future perfect in open and cooperative systems. In Proc. of HCI'94. Cambridge University Press, 1994, 397-408.

[4] Dix, A. Chapter 3: Human-Computer Interaction and Web Design. In Handbook of Human Factors in Web Design. Robert W. Proctor and Kim-Phuong L. Vu (eds). Lawrence Erlbaum, 2005, 28-47

[5] Dix, A., Levialdi, S. and A. Malizia, A. Semantic Halo for Collaboration Tagging Systems. Workshop on Social Navigation and Community-Based Adaptation Technologies, Proc. of Workshops of AH2006, Dublin: National College of Ireland, 2006, 514-521

[6] Galloway, A., Brucker-Cohen, J., Gaye, L., Goodman, E., and Hill, D. 2004. Design for hackability. In Proc. DIS'04. ACM Press, New York, NY, 2004, 363-366.

[7] Interactions Special Issue: Web technologies. Interactions, 14, 2 (Mar-Apr 2007), 33-39.

[8] Mehta, H. Usability Guru Vs. Web2.0 Community. 7 June 2007. http://comicstick.com/?p=12

[9] O'Reilly, T. What Is Web 2.0: Design Patterns and Business Models for the Next Generation of Software, O'Reilly Media, 30th Sept. 2005, (accessed 23/06/2007) http://www.oreillynet.com/pub/a/oreilly/tim/news/2005/09 /30/what-is-web-20.html

[10] Silva, P. and Dix, A., Usability - Not as we know it! In Proc. of the 21st BCS HCI Group Conference, HCI2007, Volume 2. British Computer Society, 2007.

[11] Tse, O., England, D. and Nimoy, J. What's your view on Web 2.0? Interfaces 69 (Winter 2006), 8-9. 